\title{
Dharma Therapy: A Buddhist Counselling Approach to Acknowledging and Enhancing Perspectives, Attitudes and Values
}

\author{
Sik Hin Hung and Jennifer Yim Shui Wa
}

\subsection{Introduction to the Case}

There is suffering, and it is part of life. This is an observation that the Buddha made. In fact, the core of Buddhist teaching is about suffering and the path to end suffering. The Buddha pointed out that the cause of suffering is ignorance, and by eliminating ignorance, suffering can be eliminated. With ignorance, people would develop delusive perspectives, attitudes and value, and, as a result, behave unwisely and bind oneself into all kind of difficulties and sufferings. What the Buddha meant by 'delusive' is the mistaken or dogmatic understanding of reality. The path to eliminate ignorance begins by being aware that there is suffering and developing right view and understanding of realty through the practice of mindfulness and careful attention [1]. The above explanation of the relationship between ignorance and suffering is the core of the Buddhist teaching, the Law of Dependent Origination.

This Buddhist understanding of suffering is the theoretic foundation of Dharma Therapy, a psycho-social intervention that incorporated mindfulness practice and other Buddhist cognitive training to help clients to develop right view and understanding of the stressful situation that they are dealing with. There are a total of seven steps to Dharma Therapy. In the following is a discussion as to how we applied Dharma Therapy to help Mr. Peter Chan to deal with his psychological problems.

S. H. Hung

Centre of Buddhist Studies, University of Hong Kong, Hong Kong, China

J. Y. S. Wa $(\square)$

Tsz Shan Monastery Buddhist Spiritual Counselling Centre, Hong Kong, China

(C) The Author(s) 2021

D. Stoyanov et al. (eds.), International Perspectives in Values-Based Mental

Health Practice, https://doi.org/10.1007/978-3-030-47852-0_35 


\subsection{Case Narrative}

Peter Chan is a 48-year-old Hong Kong Chinese man who was feeling lost and could not find meaning in his life after both parent died one after the other within a year. He is married for over 18 years with no children. Relationship with wife is good and is supportive of each other.

Five years ago, his father was diagnosed to have cancer. The treatment was not effective at all. His father finally gave up all treatments and died half a year later. Unfortunately, his mother blamed herself for not insisting on offering more treatment for her husband. Her guilt drew her into a mental state of depression and eventually jumped to her death. Peter was shocked by her mother's sudden death and felt very sad. He had a contradictory feeling between of not taking good care of his mother, but at the same time, having a feeling of relieve as he didn't know how to deal with his mother's depression. Consequently, his emotion became unstable and developed insomnia. Furthermore, his work as a designer is exerting tremendous pressure on him and he could not concentrate on his work. Eventually, he was diagnosed to have anxiety and panic disorder by his psychiatrist who also gave him 6 months sick leave.

During his sick leave, Peter seek help from a Buddhist counselling center and reported that he had the following problems: whenever he smelt burning incense, raw meat in the market and rotten things, his heartbeat accelerated, felt stuffy and tightness in his chest and panted with heavy sweat. At the same time, he was very anxious and afraid that other people would take notice of his problem. As a result, he wanted to run away and hide from crowded places. He had similar emotional experience before when he was laughed at by some colleagues during a presentation at work. His mind went blank, not until his hands started shaking continuously that he regained consciousness. At that moment, he found himself hidden somewhere in a corner of the room holding his own shaking hand.

After these emotional episodes, Peter noticed that he could no longer control his thought even though he tried. He used to be rational and have a strong willpower to control everything. However, his anxiety and panic attack made him felt helpless and annoyed. He was afraid that his illness would become uncontrollable and could not be cured. Nevertheless, he expected the problem to be resolved with the hope that his life would go back to normal soon.

\subsection{Values Arising}

During the counselling sessions, the counsellor followed the seven steps of Dharma Therapy [2]:

1. Introduction and preparation session.

2. Become aware of the suffering and unsatisfactory conditions of the current situation.

3. Develop a desire to be liberated from the suffering. 
4. Question and investigate the cause of suffering.

5. Observe and learn by paying careful attention to suffering and the cause of suffering.

6. Developing insight and wisdom as to how to bring an end to suffering and the cause of suffering.

7. With insight and wisdom, take the necessary steps to bring an end to suffering.

During the introduction and preparation session, the counsellor explained to Peter that she is only a facilitator to guide and support him on the path to recovery; it is his own motivation and effort that will eventually heal and transform him. Buddhism is a religion that takes the view that we are all responsible for our own thought and behaviour. Other people can only help and educate you to become aware of the problem and causes of the problem. To facilitate the arising of awareness, mindfulness was introduced to Peter to help him build a spiritual oasis where there would be peace and clarity. This is important because the client must first need to acknowledge and learn to live with the present situations, however painful, before he/she can transform or move on to other more satisfactory conditions.

In the second step of the therapy, the therapist guided Peter to become more aware of the unsatisfactoriness of the situations that he is in so that he could develop a stronger commitment to the therapy. At the same time, she helped him to classify the external issues and emotional sufferings that he was facing into two groups: those that he has no choice but has to accept and those that he has an option to change and modify.

During this explorative step, Peter revealed that he felt powerless in face of his parent's death, however, being a man and a successful person, he believed that he should be in charge of his life and be on top of his emotions. But he can't. His depression and anxiety were too much for him to handle. So he had to seek help form the psychiatrist and the counsellor. Furthermore, he felt that being a son, he should have taken care of the well-being of his parent out of filial piety. Now that they have both died tragically, and he felt a sense of shame and guilt; it is a failure on his part because he could not manage his family and live up to the classical value of: "in order to govern the country, one needs to first manage his family; in order to manage his family, he needs to first improve himself" [3].

In the third step of the therapy, Peter was guided by the counsellor to see that there are causes and conditions to his pain and suffering, and with these causes and conditions, pain and suffering would bound to arise. However, there are some pain and suffering that needs not continue. Those are the emotional sufferings that arise due to the subjective perspectives, attitudes and values that Peter held on the tragic deaths of his parent. If Peter can change or update those perspectives, attitudes and values in a more wholesome way, those emotional sufferings could be eliminated. It was necessary for Peter to understand that suffering is dependently originated and will cease to be when causes and conditions stop to be and vice versa as according to the Law of Dependent Origination. Therefore, it was possible for him to escape from the suffering that he was experiencing if he aspires to change the causes and conditions that give rise to his suffering. However, at this stage of the therapy, it is 
not necessary for Peter to challenge or question those perspectives, attitudes and values because he may not be ready to alter his believe system yet.

The therapist also recommended that Peter should be more compassionate towards himself and accept the fact that he is only an ordinary person. Having compassion towards himself would allow Peter to see that it is normal and reasonable to have painful emotions while experiencing these tragic events. Moreover, being an imperfect world, there will always be imperfection, and we should not expect that everything that we do to be perfect and just right. In Peter case, allowing himself to justifiably live with the pain and suffering was very healing.

Step four of the Dharma Therapy is to help Peter to develop a better understanding of the importance of his mind, more precisely, his thought, perspectives, attitudes and values, and how his thought, perspectives, attitudes and values are correlated to the suffering that he is experiencing. In order for a person to be able to observe the working of his own mind, the practice of mindfulness and meditation is important. By now, Peter had been practicing mindfulness for several weeks, he was instructed to investigate, pay careful attention to and become aware of what is happening in his mind: his thought, perspectives, attitudes and values, and how these mental factors influence his emotions, in order to develop the insight and wisdom that are necessary to bring about the transformation of his suffering.

Step five of the therapy was to help Peter solidify the knowledge and wisdom that he gained from observing the working of his mind. He needed to re-examine which are the facts and events that he needed to accept, for example his parent death, and which are the subjective thought, perspectives, attitudes and values that he can change or update with a more wholesome angle, for example a man should always be on top of his emotions. He was guided to use the Buddhist concept of a person, the five aggregates: form, sensation, perception and thought, volition and consciousness, as a framework to help him develop a better understanding of the working of his mind and, particularly, the relationship between his thoughts, values, emotions and panic distress. The following is an example showing how the mindful process can help him develop a better understanding of the working of his mind in order to be able to deal with his anxiety and panic distress skilfully.

Peter's perceptions, thoughts and values that give rise to his sufferings:

- Death could come so sudden, it is so horrible.

- Embarrassing experience at work: Being laughed at by colleague while he was performing poorly during an introduction of a picture that he created.

- Feeling weak and helpless due to strong emotions such as anxiety and panic attacks.

- Fearing that things will get out of control and he will become useless.

Corresponding volitions that arose due to his perceptions, thoughts and values:

- I want to fight and reject anxiety and other emotions.

- I want to escape from the fact that my parents have passed away, as well as the complex emotions and fears of death. 
- Excessive self-protection and defence against dislikes.

- I want to resume and maintain "I am rational and calm," "Life is controllable".

- Eliminate emotions such as anxiety.

- Pursue to get everything back to "normal" and "controllable".

Finally, in Peter's mind and consciousness, he sees that:

- I am the one who is experiencing all sufferings because of parents' death;

- I deserved the suffering because I have not taken care of my parents: self-blaming and grief;

- I felt shameful because my emotional reaction affects my performance at work;

- I should be rational and able but I am losing control of life.

Through the intervention process, Peter understood that a person is made up of five aggregates: form, sensation, perception, volition/mental formation and consciousness. They are interdependent on each other. He also understood that perceptions and thoughts are not facts (Thought rumination); he should be mindful and prevent thoughts from falling into criticism and repetition; he should also examine the excessive attachment to self-identity.

In step six of the therapy, Peter was guided to further examine the context and assumption of the thought, perspectives, attitudes and values that he hold. With a better understanding of the context and assumption behind the thought, perspectives, attitudes and values, he can decide either to hold on to those thought, perspectives, attitudes and values or update/drop them all together. For example, he was suggested to see that his perspective: a man should always be on top of his emotions was built on the context that man should always be strong. However, such a perspective is only culturally based and it is, in many respects, emotionally unwholesome. Therefore, it is perfectly fine for him to feel distress while facing the tragic deaths of his parent.

In step seven, with the updated thoughts, perspectives, attitudes and value, Peter was advised to apply them into his daily life to bring about a transformation. Actually, the transformation just happened slowly without much effort as Peter developed a better understand of the thoughts, perspectives, attitudes and values that he hold. All these transformations happen as a result of the deeper and more wholesome comprehension of the original problem as seen from the perspective of the Dharma, that is all phenomena arise from causes and conditions, and when causes and conditions changes, those phenomena will cease to be or changes accordingly. This also applies to the suffering that Peter was experiencing.

For the end of the Therapy, Mr. Chan was able to resume his lives both in work and daily life. He was able to manage his anxiety and work stress. He also stops taking medication as the psychiatrist also found that he no longer needs the medication.

More importantly, he continues to practice meditation daily which helps him to maintain a mindful and clear mind. Cognitively, he now accepts that life is impermanence. He is now more comfortable with himself while acknowledging that his 
parents have passed away, something that is beyond his control. He has now learned to enjoy the present moment especially the time with his wife. The evaluation feedback and assessment also showed that his stress, anxiety, depression level have decreased, and his well-being increased after 14 sessions of Dharma Therapy.

\subsection{Conclusion}

Dharma Therapy was very effective in helping Peter to alleviate the suffering that he experienced as a result of the death of his parent. Through the building of the spiritual oasis, Peter was able to regain some control and clarity of his mind, and as a result, he was guided to become mindful of the content and working of his mind. Through the evaluation of the thoughts, perspectives, attitudes and values that he hold, he was able to let go of old attachments and develop new wholesome perspectives, attitudes and values. With these new perspectives, attitudes and values, Peter developed a more wholesome and healthy way of life.

Building on the Buddhist teaching of the Law of Dependent Origination, Dharma Therapy does seem to be able to help client to effectively deal with their psychological problems. This effectiveness hinges on whether the client is able to develop comprehension and insight of the cause and conditions that lead to suffering. Once the client makes sense of the interaction among his mind contents, action and consciousness, he would be able to manage his feelings and emotions more skilfully and improve overall mental health.

Like other mindfulness intervention, a Dharma Therapy counsellor's own mindfulness and/or meditation practice is very importance to the successful implementation of the intervention.

Acknowledgements This article is based on a real case story which has been anonymized, and we are very grateful that the client agrees to give us the permission to publish his story as a case study. Dharma Therapy is now being used by all the compassionate counsellors of the Tsz Shan Monastery Buddhist Spiritual Counselling Centre to help to alleviate sufferings of their clients.

\subsection{Guide to Further Sources}

For further information please refer to the following links:

(a) A Randomized Controlled Trial of Awareness Training Program (ATP), a Group-Based Mahayana Buddhist Intervention. https://link.springer.com/article/10.1007/s12671-018-1082-1

(b) Repetitive Religious Chanting Modulates the Late-Stage Brain Response to Fear- and Stress-Provoking Pictures. https://www.frontiersin.org/articles/10.3389/fpsyg.2016.02055/full

(c) Entrainment of chaotic activities in brain and heart during MBSR mindfulness training. https://www.sciencedirect.com/science/article/pii/S0304394016300015 
For Dharma therapy being used in an intervention program with mindfulness as one of its key components, please see:

Kwee MGT (Ed.). New horizons in Buddhist psychology: relational Buddhism for collaborative practitioners. Chagrin Falls, OH: Tao Institute Publications; 2010. p. 353-72.

\section{References}

1. Bodhi BT. The connected discourses of the Buddha: a new translation of the Sanyutta Nikaya. Boston: Massm Wisdom Publications; 2000.

2. Sik. Dharma therapy: an intervention program with mindfulness as one of its key components [Internet]. HKU Scholars Hub: Home. Tao Institute Publications; 1970 [cited 2019 Dec 6]. http://hub.hku.hk/handle/10722/128225.

3. Confucius. The Book of Rites. Da Xue. James L, translator. The United States: Createspace Independent Publishing Platform; 1885.

Open Access This chapter is licensed under the terms of the Creative Commons Attribution 4.0 International License (http://creativecommons.org/licenses/by/4.0/), which permits use, sharing, adaptation, distribution and reproduction in any medium or format, as long as you give appropriate credit to the original author(s) and the source, provide a link to the Creative Commons license and indicate if changes were made.

The images or other third party material in this chapter are included in the chapter's Creative Commons license, unless indicated otherwise in a credit line to the material. If material is not included in the chapter's Creative Commons license and your intended use is not permitted by statutory regulation or exceeds the permitted use, you will need to obtain permission directly from the copyright holder. 